Lepr Rev (1984) 55, 41-46

\title{
Treatment of ulnar and median nerve function loss in borderline leprosy
}

\author{
ELS M J TOUW-LANGENDIJK, J W BRANDSMA \& \\ J G ANDERSEN \\ All Africa Leprosy and Rehabilitation Training Centre (ALERT), \\ P.O. Box 165, Addis Ababa, Ethiopia
}

Accepted for publication 16 June 1983

\begin{abstract}
Summary A rigid cortico-steroid treatment regimen was given to borderline leprosy patients who had recent nerve function loss due to reversal reaction. In order to record nerve function changes objectively a nerve index was used which was based on the results of voluntary muscle testing and sensory testing. Ninety-three ulnar and median nerves were followed in this study. Improvement in ulnar nerve function was obtained in $60 \%$ and in the median nerve in $67 \%$. Overall improvement was better in BL nerves $(85 \%)$ when compared with BT nerves $(51 \%)$. The results show a more rapid recovery of median nerve function as compared to the ulnar nerve. There was a slightly better recovery of nerve function in previously untreated leprosy patients $(69 \%)$ as compared to patients who developed nerve function loss while on anti-leprosy treatment $(59 \%)$.
\end{abstract}

\section{Introduction}

Nerve damage in reversal reaction is a well-known complication in leprosy. ${ }^{1-4}$ It occurs in patients in the borderline group of leprosy and may be due to a sudden change in cell-mediated reactivity, although the triggering factor is unknown..$^{5,6}$ During reversal reaction there is an inflammatory reaction at those sites where leprosybacili are found, that is in the skin and in the nerves. The inflammatory reaction in the nerves, the so-called neuritis, can result in sudden nerve damage. If this reaction is not treated quickly, then permanent nerve function loss may be the result. Drugs such as cortico-steroids should therefore be given to suppress this reaction. The drug in common use is prednisolone. The use of cortico-steroids in leprosy reactional states is not new and they have been used since the start of the use of DDS in leprosy. ${ }^{7-10}$ The dosage, ${ }^{11,12}$ the duration of therapy ${ }^{13}$ and the route of administration ${ }^{14}$ have all been a topic for discussion in the past, but there is still no collective agreement on the subject. ${ }^{15}$ In order to assess the effect of 
cortico-steroid treatment it is necessary to measure the function of a nerve during and after treatment. For this purpose several parameters are available. In this study Sensory Testing (ST), Voluntary Muscle Testing (VMT) and Motor nerve Conduction Velocity (MCV) measurements were the techniques used to assess nerve function.

A group of patients with recent nerve damage were followed in this study during and after a fixed regimen of cortico-steroid treatment.

\section{Materials and Methods}

Thirty-six leprosy patients, twenty-four borderline tuberculoid (BT) and twelve borderline lepromatous (BL) were followed up for 1 year after they received a 6-month course of prednisolone for recent nerve function loss of the ulnar and median nerves. Patients were given $40 \mathrm{mg}$ prednisolone daily for the first 2 weeks followed by $30 \mathrm{mg}$ daily for the next 2 weeks. Thereafter the dosage was reduced by $5 \mathrm{mg}$ every month. All patients received $100 \mathrm{mg}$ DDS daily as anti-leprosy treatment. A total of 93 nerves, 53 ulnar and 40 median nerves, were followed in this study, an average of 2.6 nerves per patient.

For sensory evaluation we used the technique described by Naafs,${ }^{16}$ using a set of bristles with different diameters. The skin was touched with each bristle (Figure $1)$ in five different places. Every stimulus felt scored 2 points. Therefore the maximum sensory score for a nerve would be $50(5 \times 5 \times 2)$ points. For muscle testing we used the tests described by Brandsma. ${ }^{17}$ For the ulnar nerve abduction of the little finger, and for the median nerve abduction of the thumb were tested. The scoring, according to the MRC scale ${ }^{18}$ was multiplied by a factor 10 thus also giving a maximum score of 50 for normal motor function of the nerve.
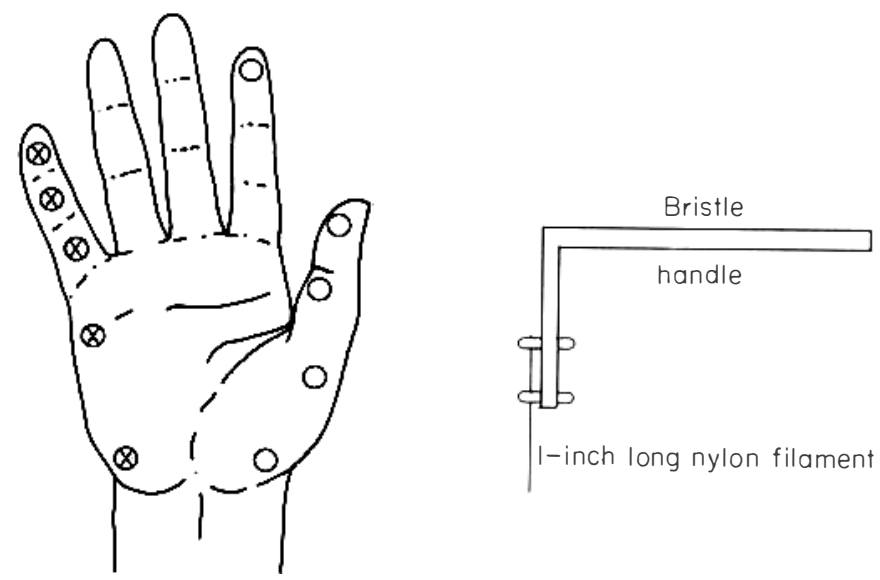

Figure 1. Diagrams of a bristle used for sensory testing and the areas tested. $\bigcirc$, areas for stimuli for the median nerve. $\otimes$, areas for stimuli for the ulnar nerve. 
Motor nerve conduction velocity was assessed as described by Naafs. ${ }^{19}$ Here also a grading scale was developed whereby the score for the conduction of the whole nerve was added to the score of the most affected segment of that nerve (Table 1).

The Nerve Index is defined as being the VMT score added to the ST score giving a score of 100 for a normal functioning nerve. In the Extended Nerve Index the $\mathrm{MCV}$ is added to the Nerve Index.

An increase of at least 15 points was considered an improvement, a loss of more than 15 points deterioration. A change of less than 15 points either way was regarded as status quo. Only patients with nerves with an initial score of 70 or less on the Nerve Index were admitted to the study. In addition the duration of nerve function loss was required to be less than 6 months.

\section{Results}

In 29 patients $(80 \%)$ the nerve function improved; it remained unchanged in four patients and three patients showed deterioration of one nerve.

Thirty-two $(60 \%)$ of the 53 ulnar nerves improved as did $27(67 \%)$ of the 40 affected median nerves, thus giving a total of $59(63 \%)$ improved nerves. Figure 2 shows the average improvement of these nerves. It will be seen that the median nerve was less affected from the start. More marked improvement was also observed in the median nerve during the first 2 months than during the following 4 months: virtually no further improvement was noted after that period. This contrasts with the ulnar nerve where initial improvement was slower, but still continued after 6 months of treatment.

Table 2 relates the recovery to classification of the patients and whether patients were already on treatment when they developed nerve function loss.

\section{Discussion}

This study is a preliminary report of a much larger trial of 133 patients and is a report on the first 36 patients who had completed a follow-up of 1 year. The trial

Table 1. Scoring for motor nerve conduction velocity

\begin{tabular}{lr}
\hline $55 \mathrm{~m} / \mathrm{sec}$ or more & 25 points \\
$50-54.9 \mathrm{~m} / \mathrm{sec}$ & 20 points \\
$40-49 \cdot 9 \mathrm{~m} / \mathrm{sec}$ & 15 points \\
$30-39.9 \mathrm{~m} / \mathrm{sec}$ & 10 points \\
$20-29.9 \mathrm{~m} / \mathrm{sec}$ & 5 points \\
below $20 \mathrm{~m} / \mathrm{sec}$ & 0 points
\end{tabular}



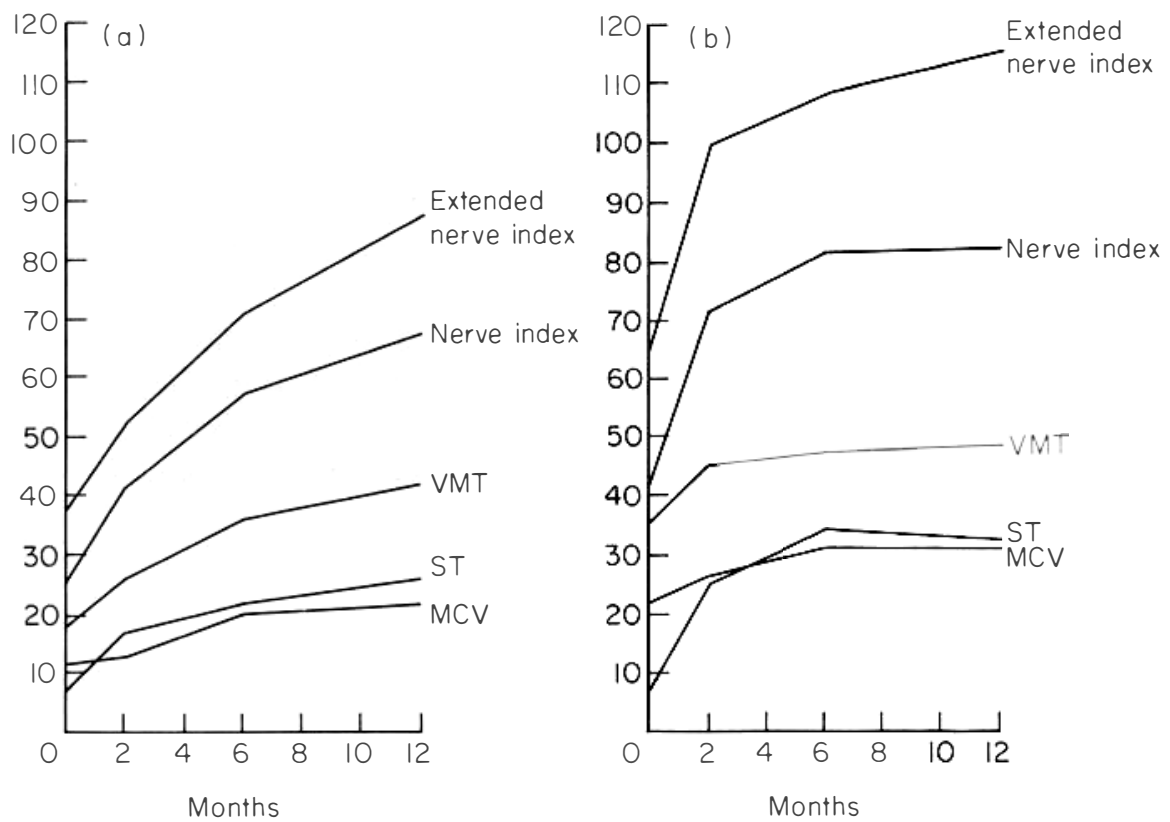

Figure 2. Improvement of (a) 32 ulnar nerves, and (b) 27 median nerves.

was designed to establish the effect of cortico-steroid treatment on neural damage during reversal reaction. ${ }^{20}$ The anti-leprosy treatment reflects the situation prior to the introduction of multi-drug therapy as recommended by WHO. It has been suggested that cortico-steroids should be given for nerve function loss in reversal reaction at a relatively high dose for a prolonged time to be effective and to prevent recurrence..$^{13}$ These considerations led to the choice for the cortico-steroid treatment as used in this study. Side-effects can be expected at high dosages of steroids and for this reason patients were admitted to hospital during the first 2

Table 2. Nerve function recovery

\begin{tabular}{lccc}
\hline & $\begin{array}{c}\text { No. } \\
\text { patients }\end{array}$ & Nerves & Improved \\
\hline BT & 24 & 59 & $30(51 \%)$ \\
BL & 12 & 34 & $29(85 \%)$ \\
New patients & 17 & 39 & $27(69 \%)$ \\
Treated patients & 19 & 54 & $32(59 \%)$ \\
\cline { 2 - 4 } Total & 36 & 93 & $59(63 \%)$ \\
& & &
\end{tabular}


months of treatment. With this treatment no serious side-effects were encountered.

The VMT and ST are easy to reproduce and easy to perform. The idea of the Nerve Index is based on a publication by Naafs, ${ }^{20}$ who introduced the Nerve Deficit Index as an index of the nerve function. In the present Nerve Index we have left out the scoring for pain, tenderness and enlargement of the nerve because they are subjective. In our results there is a marked difference between the rates of recovery of the ulnar and median nerves. One explanation might be the difference in anatomical level of nerve involvement. The difference can certainly also be explained by the initial higher VMT score of the median nerve.

When the study was started it was discussed whether the classification of the patient or prior treatment were important to the patient's response to treatment for recent nerve damage. Table 2 shows that $\mathrm{BL}$ patients responded more favourably to the treatment than BT patients. The number of BL patients, however, is small and nerve function loss in these patients may recur. A larger observation group and a longer observation time may show more definite results. There were no major differences between treated and untreated patients.

$\mathrm{MCV}$ is useful in a trial like this as another means of objectively assessing nerve function but for the follow-up of nerve function in treatment trials it is not absolutely necessary. No new prognostic indications are added by this method.

The Nerve Index gives a good indication of the nerve function in a leprosy patient as it gives a good picture of the changes of nerve function in treatment trials and is also valuable in the follow-up of nerve function in individual patients.

\section{References}

1 Cochrane RG. Neuritis in leprosy. In Leprosy in the and Practice. Cochrane RG, Davey TF (eds), 2nd. ed., 1964; 410-17.

2 Cochrane RG. Complicating conditions due to leprosy. See Bristol, John Wright and Sons 1; 331-3.

3 Jopling WH. Handbook of Leprosy. 2nd ed. Heinemann, 1978; 66-74.

4 Ross WF, Pearson JMH. The recognition and management of nerve damage under field conditions. Lepr Rev, 1975; 46: 231-4.

5 Bryceson A, Pfaltzgraff RE. Leprosy. 2nd ed. Churchill Livingstone, 1979; 65-71.

6 Pearson JMH, Ross WF. Nerve involvement in leprosy. Pathology, differential diagnosis and principles of management. Lepr Rev, 1975; 46: 199-212.

7 Browne SG. Corticosteroids in leprosy. A guide to their systemic use. Lepr Rev, 1964; 35: $157-63$.

8 Jopling WH. Treatment of acute phases (reactional states) in lepromatous leprosy. See Cochrane RG \& Davey TF 1: 418-24.

9 Jopling WH, Cochrane RG. The place of cortisone and corticotrophin in the treatment of certain acute phases in leprosy. Lepr Rev, 1957; 28: 5-10.

10 Lowe J. ACTH and cortisone in treatment of complications of leprosy. $\mathrm{Br} \mathrm{Med} \mathrm{J,} \mathrm{1952;} \mathrm{746-9.}$

11 Bryceson A, Pfaltzgraff RE. Management of reactions. See 5: 72-6.

12 Waters MFR. Treatment of reactions in leprosy. Lepr Rev, 1974; 45: 337-41.

13 Naafs B, Pearson JMH, Wheate HW. Reversal reaction: Prevention of permanent nerve damage. Comparison of short and long term steroid treatment. Int $J$ Lepr, 1979; 47: 7-12. 
14 Tio TH. Neural involvement in leprosy. Treatment with intraneural injection of prednisolone. Lepr Rev, 1966; 37: 93-7.

15 Pearson JMH. The use of corticosteroids in leprosy. Lepr Rev, 1981; 52: 293-9.

16 Naafs B, Dagne T. Sensory testing. A sensitive method in the follow up of nerve involvement. Int J Lepr, 1977; 45: 364-9.

17 Brandsma JW. Basic nerve function assessment in leprosy patients. Lepr Rev, 1981; 52: 161-71.

18 Medical Reseach Council Memorandum. Aids to the investigation of peripheral nerve injuries. (Memo. no. 7), 2nd ed. London; HMSO, 1962.

19 Naafs B, Pearson JMH, Baar AJM. A follow up study of nerve lesions in leprosy during and af ter reaction using motor nerve conduction velocity. Int J Lepr, 1976; 44: 188-97.

${ }^{20}$ Naafs B, van Droogenbroeck JBA. Assessment of nerve function in leprosy. Proceedings 11 th. Int Lepr, Congress, Mexico, 1978. Abstract 8b, 270. 